\title{
AVALIAÇÃO PSICOLÓGICA DO ESTRESSE OCUPACIONAL DOS BOMBEIROS MILITARES DE PERNAMBUCO: UMA NECESSIDADE
}

\author{
José Francisco de Arruda Filho ${ }^{1}$ \\ Ana Paula Paes Andrade ${ }^{2}$
}

\section{RESUMO}

Esta pesquisa teve por objetivo apresentar uma proposta de avaliação psicológica para o estresse ocupacional sofrido pelos integrantes do Corpo de Bombeiros Militar de Pernambuco (CBMPE), que vivenciam mortes, sofrimento, perdas de companheiros e situações acima das suas possibilidades pessoais de solução. Tem como objetivos específicos, correlacionar informações sobre os afastamentos do serviço e o estresse ocupacional, destacar os principais tipos de ocorrências atendidas pelo CBMPE, sugerir técnicas e testes psicológicos mais adequados, bem como, as condições necessárias para a realização da avaliação psicológica do estresse ocupacional e levantar informações sobre a realização deavaliação psicológica do estresse ocupacional em outras corporações BM no Brasil. Sendo o objeto de estudo um recorte temático sobre o adoecimento no trabalho pelo estresse ocupacional, o método utilizado foi o qualitativo e a pesquisa foibibliográfica e documental. Concluiu-se que a avaliação psicológica pode e deve ser usada para monitorar e, consequentemente, minimizar os transtornos físicos e psíquicos causados pelo estresse ocupacional em integrantes do Corpo de Bombeiros Militar de Pernambuco A carência de publicações sobre cultura organizacional em corporações bombeiros militares, e os dados incompletos sobre os motivos das dispensas médicas que afastaram BM do serviço, foram variáveis limitadoras desta pesquisa.

Palavras-chave: bombeiro militar; estresse ocupacional; avaliação psicológica.

\footnotetext{
${ }^{1}$ Oficial do Corpo de Bombeiros Militar de Pernambuco, graduado pela Academia de Policia Militar do Paudalho (1990); Graduado em Psicologia pela Faculdade Integrada do Recife (2013); Pós-Graduado em Psicopedagogia pela Universidade do Estado do Rio de Janeiro - UERJ (2000) e em Avaliação Psicológica pela FAFIRE (2016); especializado em Atendimento Pré-hospitalar pela FENSG/UPE (1992) e em Técnicas de Ensino pelo Centro de Estudos de Pessoal - CEP/ EB - RJ (1997).

2 Graduada em Psicologia do Trabalho pela Faculdade de Filosofia do Recife (FAFIRE-1988), com Licenciatura em Psicologia pela FAFIRE (1987); Pós-graduada em Psicologia Organizacional e do Trabalho pela FAFIRE (2007), Professora de Cursos de Extensão na área de Gestão de Pessoas com ênfase em testes psicológicos e de Pós-graduação em avaliação psicológica na FAFIRE.
} 


\title{
PSYCHOLOGICAL EVALUATION OF THE OCCUPATIONAL STRESS OF THE MILITARY FIREFIGHTERS OF PERNAMBUCO: A NECESSITY
}

\begin{abstract}
This research had as objective, to present a proposal for a psychological assessment for occupational stress suffered by firefighters of the Military Fire department of Pernambuco (CBMPE), whose members experience death, suffering, loss of comrades, above situations of your personal possibilities solution. Its has as specific objectives, correlate information about the departures of service and occupational stress, highlight the main types of events attended by CBMPE suggest techniques and appropriate testing, as well as the necessary conditions for the realization of psychological assessment of occupational stress and gather information on conducting monitoring of occupational stress in other corporations of military firefighters in Brazil. As the study theme clipping object about monitoring illness at work by occupational stress. The method used was qualitative and the research was literature and documents. It is concluded that the psychological evaluation can and should be used to monitor and hence minimize the physical and psychological disorders caused by occupational stress in members of the Fire Brigade of Pernambuco. The lack of organizational culture remains publications firefighters corporations and incomplete data on the grounds of medical dispensations that military firefighters away from the service, were limiting variables of this research.
\end{abstract}

Keywords: military firefighter; occupational stress; psychological evaluation.

\section{Artigo Recebido em 12/11/2016 e Aceito em 11/05/2017}

\section{INTRODUÇÃO}

Os bombeiros estão diariamente sujeitos a agentes estressores durante a sua prática profissional, como ruídos, chuva, calor, frio, esforço físico. 
Vivenciam mortes, sofrimento, perdas de companheiros, situações acima das suas possibilidades pessoais de solução. Essas circunstâncias acabam por possibilitar o surgimento de sentimentos como desânimo, desapego, irritabilidade, estado de hipervigilância, reiteração do evento (pesadelos e lembranças das causas do estresse emocional), desinteresse em atividades significativas, dificuldade de concentração e transtornos psicossomáticos.

A avaliação psicológica como ferramenta de aferição de vários fenômenos psíquicos, poderia ajudar a reduzir este sofrimento? Avoglia (2012) esclarece que elaabrange os fenômenos que envolvem desajuste emocional, sofrimento psíquico, relacionamentos interpessoais, e permite a emissão de diagnósticos e prognósticos levando em consideração o contexto do sujeito e suas potencialidades, não focando apenas em suas patologias. Logo, a resposta é sim.

Por quê, então, a avaliação psicológica não é usada para monitorar e, consequentemente, minimizar os transtornos físicos e psíquicos causados pelo estresse ocupacional em integrantes do Corpo de Bombeiros Militar de Pernambuco?

Foram levantadas três hipóteses. A primeira foi de que o bombeiro militar estaria imune aos efeitos do estresse por se perceber como um "herói";a segunda, que o CBMPE não sabe como realizara avaliação psicológica necessária e, finalmente, que a corporação não percebe a relação de causalidade entre o estresse ocupacional e o adoecimento do sujeito.

A relevância desta pesquisa evidenciou-se no fato de que o estresse ocupacional é inerente à atividade bombeiro militar (BM), portanto, precisa ser avaliado para que sejam implantadas políticas de gestão de pessoas na corporação, que levem em consideração os resultados desta avaliação, utilizando-os na seleção, formação de pessoal e protocolos de atendimento a ocorrências. 
O método utilizado foi o qualitativo, haja vista que lidamos com a interpretação de fenômenos sociais (DIAS \&TRALDI, 2011).A pesquisa foibibliográfica e documental. A coleta de dados nas corporações $B M$ atende ao que teóricos como Minayo (2011), Traldi (2011), Prestes (2007) e Vergara(2003), afirmam, que a importância da pesquisa ser feita na localidade onde possivelmente ocorre o fenômeno e onde há pouco conhecimento divulgado sobre seus efeitos no grupo específico. Coletaram-se informações das outras corporações BM, através da presidência da Liga Nacional de Bombeiros Militares e, no CBMPE, através de e-mail respondido pela Diretoria de Gestão de Pessoas e por todos os comandantes de Unidade Operacional, sobre dispensas e licenças médicas, analisando osdados estatísticos operacionais de 2011 a 2015 e consultando a Lei de Organização Básica da corporação.

Dias e Traldi (2011) orientam que se busque, através de fontes secundárias, o "estado da arte", ou seja, o que já foi publicado sobre o estresse ocupacional e avaliação psicológica, pelos principais teóricos que abordam o objeto de estudo deste trabalho, como Zanelli (2004), Benevides-Pereira (2010), Lago e Codo (2010), Cunha (2003) e Pasquali (2001).

O objetivo geral deste trabalho foi sugerir uma proposta de avaliação psicológica do estresse ocupacional dos integrantes do CBMPE. Tendo como objetivos específicos, correlacionar informações sobre os afastamentos do serviço e o estresse ocupacional; destacar os principais tipos de ocorrências atendidas pelo CBMPE; sugerir técnicas e testes mais adequados, bem como, as condições necessárias para a realização da avaliação psicológica do estresse ocupacional e levantar informações sobre a realização desta atividade em outras corporações BM no Brasil.

A carência de publicações sobre cultura organizacional em corporações bombeiros militares e os dados incompletos sobre os motivos das 
dispensas médicas que afastaram o BM do serviço, foram variáveis limitadoras desta pesquisa.

\section{EVOLUÇÃO DA CULTURA ORGANIZACIONAL DO CBMPE}

\subsection{História do CBMPE}

Em 1636, durante o domínio holandês no Brasil, com o objetivo de combater incêndios em edificações, foi criado, em Recife, o primeiro serviço de extinção de incêndios, a Companhia dos Brantmeesters. Sendo este o primeiro serviço de combate a incêndios das Américas. A preocupação em proteger das chamas, o patrimônio e as pessoas vêm de longa data. Contudo, por fatos históricos que não serão mencionados neste trabalho, este serviço não teve continuidade até os dias atuais, então, a corporação considera, como data oficial de criação, 20 de outubro de 1887, quando foi ativada para não mais deixar de existir, a Companhia de bombeiros do Recife, instalada na Praça Joaquim Nabuco.

Este serviço era mantido financeiramente pelas companhias de seguros do Recife, haja vista que havia muitos incêndios criminosos e estes, estavam causando prejuízos àquelas empresas. Seu primeiro comandante foi o Cap Joaquim José de Aguiar, oriundo do Corpo de Bombeiros imperial (CAVALCANTI, 2007).

A Lei de Organização Básica do CBMPE (PERNAMBUCO, 2013) define como missão, realizar serviços específicos de bombeiro militar e atividades de defesa civil na área do Estado de Pernambuco, o que engloba basicamente realizar vistorias técnicas e análise de projetos de incêndio, salvamento de vítimas em ambiente terrestre, aquático e em locais elevados, prevenir e combater incêndios em áreas urbanas e florestais. 
Desde o início de sua existência, os bombeiros eram reconhecidos como abnegados e intrépidos. Homens corajosos que combatiam os incêndios. Tendo participado ativamente das revoluções de 1930 e 1964, os bombeiros tiveram que limpar baias da cavalaria da Polícia Militar e dormir ao relento (estando de serviço) antes de terem o reconhecimento que têm hoje. Cogitouse até mesmo pintar as viaturas de azul, pois, "vermelho era cor de comunista". Os dados históricos foram retirados da obra "Guerreiros da Paz", Cavalcanti (2007).

Na mesma obra há registros de feitos relevantes de ex-comandantes da corporação, bem como, da atuação dos bombeiros em grandes incêndios: no mercado do derby (1900); na Alfândega do Recife (1912); no Cineteatro Elvética (1920); na Casa de banhos (1924); no teatro Valdemar de Oliveira (1980); No mercado de São José (1989); cheia de 1975; no navio Jatobá (1985), bem como, no resgate de vidas na cheia de 1975.

\subsection{Cultura organizacional}

Compreender a cultura organizacional de uma instituição não é tarefa fácil, contudo, apresentaremos peculiaridades do CBMPE, considerando seus fatos históricos e condições atuais, que ajudarão a corporação, sendo que, dos avisos através dos sinos das igrejas ao videomonitoramento das ocorrências, muita coisa mudou na corporação, mas, ainda continua a exposição do bombeiro militar a um ambiente de riscos físicos, psicológicos e sociais, desconhecendo a situação real da ocorrência, por vezes com treinamento e equipamentos insuficientes. Esta atividade continua gerando elevada carga de estresse, já que retornarão para os quartéis com uma experiência de vida ou de morte, cotidianamente.

Cardoso e Cunha (2005) apresentam um conceito bastante objetivo, afirmando que cultura organizacional é um estilo de ser da organização que 
reflete na própria organização, enquanto instância coletiva e sobre os indivíduos que a compõem. Complementam ainda explicando que é construída ao longo do tempo por quatro fatores básicos: sistema de normas; o saber tecnológico (como fazer - incluindo a linguagem especializada); padrões de relações interpessoais e organização do espaço e controle do tempo e mecanismos de vigilância internalizada.

Silva e Zanelli (2004) esclarecem que o conhecimento construído e compartilhado pelos integrantes ao longo da história da organização, tornam-se concepções, normas e valores inquestionáveis que são mantidos e repassados aos novos membros através de ritos, rituais, mitos, histórias, gestos, atitudes. Este "amálgama" gera um ambiente de plausibilidade para a organização, no caso o CBMPE, que reduz a ansiedade dos seus integrantes, mas, também é uma força invisível a ser considerada em qualquer processo de mudança.

O brasão das armas do Corpo de Bombeiros Militar de Pernambuco, os cursos de formação para os novos integrantes, o lema nacional dos bombeiros militares, "Vida alheia e riquezas, salvar", a rotina diária de passagem de serviço de atendimento de ocorrências, os uniformes, entrega de medalhas, passagens de comando, a linguagem peculiar, o "nome de guerra", o banho de neblina por ocasião das promoções, as histórias contadas sobre o combate a grandes incêndios ou ocorrências de vulto e a canção do CBMPE, cujo trecho foi transcrito abaixo, mostram a correlação das informações de Silva e Zanelli (2004) com as do livro Guerreiros da paz:

De onde vem tanta força e valor que o impele tenaz a lutar? Denodado, pratica o seu lema: "VIDA ALHEIA E RIQUEZAS SALVAR". Quer nas chamas, quer nas águas, quando tudo se destrói, não se entreguem a desespero se presente o nosso herói! (grifo nosso).SALVE O CORPO DE BOMBEIROS! (CAVALCANTI, 2007, p. 15) 
Revista Científica do Corpo de Bombeiros Militar de Pernambuco

Seção 1 - Artigos Técnico Científicos

Artigo publicado no Vol.03 №7 - Edição de JUL a DEZ 2017 - ISSN 2359-4829

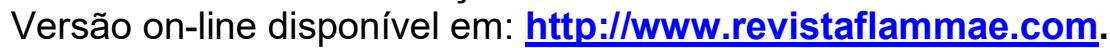

Como o bombeiro militar se percebe na corporação e enquanto integrante dela, pela sociedade? É realmente influenciado pelo ambiente organizacional?

Natividade e Brasil (2006) pesquisaram sobre a escolha profissional entre bombeiros militares e constataram que apesar de $31,5 \%$ dos sujeitos terem escolhido a profissão por casualidade, quase $90 \%$ afirmaram que escolheriam de novo, pois, sentem orgulho da profissão escolhida. No mesmo estudo, destacam que $98 \%$ da população confia nos bombeiros militares e quase $95 \%$ dos participantes do estudo afirmaram que suas famílias sentem orgulho de sua profissão.

Natividade (2009), em pesquisa realizada com bombeiros militares da cidade de Florianópolis, identificou que não consta nas queixas organizacionais, a atividade em si, mas as condições de trabalho. A percepção entre os pesquisados de que não podem errar também ficou evidente, assim como a força da cultura organizacional, pois, quase $73 \%$ dos sujeitos afirmaram que o exercício da profissão mudou o seu jeito de ser e que levam condutas da caserna para a sua vida cotidiana.

Uma destas condutas era permanecer em estado de alerta. Foi verificado por Gonzaleset al(2006),quando, em 2005, realizou pesquisa com um grupo de bombeiros militares do Estado do Rio Grande do Sul e constatou que $91,66 \%$ deles trabalhavam em estado de alerta, sendo que $63,63 \%$ destes, afirmaram estar em estado de alerta permanente. O estado de alerta permanente pode causar transtornos de sono, desgaste físico e mental que podem ocasionar desde atritos familiares até acidentes no trabalho.

Estes profissionais sentem-se realizados como bombeiros militares, apesar de trabalharem diariamente em ambientes inóspitos, lidar com o sofrimento alheio, tendo a morte como companheira de profissão, e não podendo deixar de serem empáticos. Como este paradoxo é vivido na cultura organizacional? O controle emocional é uma qualidade exigida destes 
profissionais. Demonstrar emoção seria uma demonstração de "fraqueza". O bloqueio das emoções diante das situações de sofrimento alheio, são praticadas exaustivamente. "Heróis" não são subjugados pelas emoções. A citação de um trecho da pesquisa realizada por Capitaneo, Ribeiro e Silva (2012) expressa o conflito emocional destes profissionais no desempenho de suas atividades:

\begin{abstract}
Nesse sentido, o profissional bombeiro lida constantemente com uma forte carga afetiva em seu trabalho. Em ocorrências que envolvem vítimas, os bombeiros podem estar face a face com a morte, ou presenciar cenas muito fortes. Destaca-se que após a ocorrência, eles voltam ao trabalho sem nenhum suporte que os ajude a encarar tais situações, que, por mais cotidianas que sejam para eles, nunca deixam de ser traumáticas. Precisam agir como se nada tivesse acontecido e estar prontos para novo chamado (RIBEIRO e SILVA, 2012, p. 64).
\end{abstract}

Em pesquisa sobre a qualidade de vida dos bombeiros militares que trabalham na cidade de São Leopoldo, Rio Grande do Sul, Monteiro etal. (2007), verificou-se que os profissionais também sentiam-se inibidos em demonstrar suas dores e sofrimentos. Uma descoberta importante desta pesquisa foram os relatos de que vários bombeiros militares, apesar de sentirem o estresse, não encontram espaço entre os colegas para falar sobre ele, pois, entre eles e a sociedade prevalece a ideia de que bombeiro militar "é aquele que é forte, que não deve se queixar de nada, que deve suportar tudo" (p. 558).

A corporação bombeiro militar possui uma cultura organizacional repleta de valores e símbolos e está permeada pela representação social do bombeiro militar como "herói". Contudo, o conflito emocional entre o salvar ou não uma vítima, é parte do cotidiano operacional, gerando estresse ocupacional em alguns dos seus integrantes. 


\section{ESTRESSE}

Nos tempos modernos, a palavra estresse tornou-se comum no vocabulário popular. Frequentemente ouvem-se pessoas afirmarem que estão ou que alguém está "estressado". Percebe-se nestas afirmações que há uma confusão entre o que é estresse e o que é o estressor, o agente causador do estresse, aquilo que interfere na homeostase biológica e/ou psíquica do ser humano. Contradizendo o que muitos acreditam, o estresse não é uma doença, não está classificado como tal, nem na CID $10^{3}$ e nem no DSM - 5, entretanto, é um fator causador e mantenedor de várias patologias (SILVA, 2014).

Lambert (2006) esclarece que cada indivíduo responde ao agente estressor de forma diferente, contudo, as etapas que levam à resposta, são semelhantes. O autor, bem como, Brandão (2002), Codo, Soratto e VasquesMenezes (2004), citam o pesquisador Hans Selye, o qual, denominou as etapas de resposta ao agente estressor de síndrome geral de adaptação(grifo nosso). Esta síndrome consiste de três fases: de alarme, na qual o corpo se mobiliza para se defender do agente estressor (sobrevivência); de resistência, onde o organismo desprende ainda mais energia tentando se adaptar ao agente estressor buscando a homeostase; de exaustão, quando o organismo, não conseguindo combater o agente estressor, geralmente grave e crônico, exaure suas energias (surgimento de doenças graves) e, à medida que a situação se agrava, patologias como hipertensão, cardiopatias, gastrites, úlceras, reumatismo, artrite, imunidade baixa, transtornos mentais, também se agravam.Lipp (2015) identificou uma quarta fase, que designou de quaseexaustão. Esta fase viria antes da exaustão e se caracterizaria pelo início do adoecimento, apesar do trabalhador ainda estar conseguindo trabalhar e interagir socialmente, já não está conseguindo resistir ou adaptar-se ao agente agressor.

\footnotetext{
${ }^{3}$ Classificação Estatística Internacional de Doenças e problemas Relacionados à Saúde.
} 
Lago e Codo (2010) consideram estresse a tensão ocasionada pela ação de socorrer alguém que está sofrendo.Também conceituaram este fato de "fadiga por compaixão". Uma fadiga física e emocional resultante da compaixão que os profissionais de socorro vivenciam no seu trabalho.

\subsection{Estresse ocupacional}

Quando o trabalhador não consegue, através do trabalho, dar vazão a sua energia pulsional, esta se acumula no aparelho psíquico, sendo percebida como ameaça a sua integridade, e pode causar-lhe desprazer e tensão. (ZANELLI, 2004; DEJOURS, ABDOUCHELI e JAYET (2011).

A tensão que age sobre um trabalhador é chamada de carga psíquica por DEJOURS, ABDOUCHELI e JAYET (2011) e surge principalmente quando o trabalhador não tem liberdade para intervir na organização do trabalho. Ele sintetiza este fato na frase (p. 25): "se um trabalho permite a diminuição da carga psíquica, ele é equilibrante. Se ele se opõe a essa diminuição, ele é fatigante". E da fadiga vem a patologia.

Lent (2010) esclarece que interagimos com o meio através dos nossos sentidos e estes, são afetados pelo nível de consciência, estado emocional, doenças,ou seja, há diferenças entre o mundo real e o percebido.

Seria lógico acreditar que há uma relação direta entre sobrecarga de trabalho e insatisfação, contudo, isto não é uma regra, isto (a insatisfação) acontece quando esta sobrecarga vem acompanhada da falta de autonomia do trabalhador sobre a sua atividade (CODO, SORATTO \&VASQUES-MENEZES, 2004).

\subsection{Estresse ocupacional na atividade bombeiro militar}

$\mathrm{O}$ ambiente e as condições de trabalho dos bombeiros militares (as ruas) e o tipo de serviço (lidar com o risco e a dor do outro) são bastante adversas e imprevistas podendo trazer satisfação ao salvar, ou sofrimento, nos fracassos. 
Todos os bombeiros militares considerados aptos estão disponíveis para concorrerem a uma escala de serviço operacional. Podem realizar prevenção e combate a incêndios, salvamento aquático, terrestre e em locais elevados, bem como, aplicar os primeiros socorros a vítimas de acidentes e violência, além das ações de defesa civil.

Analisando os registros do CBMPE sobre estatísticas de atendimento de ocorrências em todo o Estado de Pernambuco, de 2011 a 2015, percebe-se que os três maiores grupos de ocorrências atendidas são atendimento préhospitalar, com média superior a $50 \%$ do total, depois, salvamento, com média de $25 \%$ e combate a incêndios com média de $10 \%$ do total. Diante destes dados, ressalta-se que na maior parte das ocorrências atendidas ocorre 0 sofrimento emocional e físico (mutilações, mortes, perdas de patrimônio, envolvimento de crianças e idosos) que afeta diretamente o bombeiro militar.

Bruck (2007) ressalta que muitas vezes, os sinais indicativos de estresse laboral podem resultar na Síndrome de Burnout.

Além do estresse causado pelos atendimentos às vítimas, os socorristas também têm que lidar com a angústia pública. Bruck (2007) aborda este tema e o define como sendo um sentimento difuso de mal-estar que se origina dos acontecimentos públicos traumáticos, chamados estressores, tais como catástrofes, desastres, acidentes de trânsito com vítima, acontecimentos que também fazem parte do cotidiano dos socorristas, como cidadão e como profissional. Na mesma obra, o autor destaca ainda que as consequências destes eventos estressores para o indivíduo vão depender da sua intensidade e do aparato psicológico para lidar com o fato. Ou seja, as reações ao mesmo fato são diferentes, mesmo para indivíduos que estejam trabalhando lado a lado. $\mathrm{O}$ trauma psíquico surge quando um estímulo é excessivo, relativamente à capacidade de adaptação do indivíduo (capacidade de dominar e de elaborar psiquicamente esses estímulos). 
Taylor (2006, apud BRUCK 2007, p. 15), classifica os bombeiros militares como vítimas de vítimas de terceiro grau: "As chamadas vítimas ocultas, constituídas pelos integrantes das equipes de primeiros auxílios, como SAMU, bombeiros, médicos, psicólogos, policiais, pessoas da defesa civil, voluntários e outros.

Lago e Codo (2010) ratificam o que Bruck (2007) denominou de angústia pública, ao abordar a traumatização vicariante, que é o dano à saúde mental do profissional (independente de gênero, idade ou nível de treinamento) que observou o sofrimento alheio ou tomou conhecimento de tal sofrimento, ressaltando que sujeito será afetado de forma única e particular.

Outra pesquisa bibliográfica e de campo, realizada por Molinet (2011), constatou que os bombeiros militares do $12^{\circ}$ Batalhão de São Miguel do Oeste, Santa Catarina, precisam de acompanhamento psicológico para lidar com o estresse ocupacional, os militares informaram como principais causas deste estresse, a relação com os superiores, a sobrecarga de funções operacionais e administrativas, $\mathrm{o}$ atendimento de ocorrências sem $\mathrm{o}$ treinamento ou equipamentos adequados, atender ocorrências com crianças ou quando tem pouca ou nenhuma informação sobre o acidente e a falta de reconhecimento, por parte dos seus superiores, pelo trabalho realizado.

De uma forma ou de outra, o ambiente interfere nas emoções e nos sentimentos dos profissionais. Mesmo que a atitude de intervir no sofrimento do outro, seja um ato nobre, não significa que os bombeiros militares estejam livres dos processos fisiológicos que são consequências desta experiência, sendo um ato de dever para eles (bombeiros), que tomam como uma missão e se comprometem a dar o máximo de si para ajudar aquele que está sofrendo.

\subsection{Saúde do trabalhador (bombeiro militar)}

A preocupação com a saúde do trabalhador vem da primeira metade do século XIX, com a revolução industrial. Na época os objetivos eram muito mais 
econômicos do que humanitários, haja vista que as perdas na produção pelas faltas por doenças eram mais relevantes do que a doença em si (MENDES e DIAS, 1991).

Complementando em alguns aspectos e ratificando outros apresentados nas pesquisas já citadas, Souza, Velloso e Oliveira (2012), através de pesquisa bibliográfica, constataram que os bombeiros militares do Brasil apresentam um quadro cada vez mais amplo de adoecimento, principalmente no que se refere à saúde mental, entretanto, este ainda é um tema pouco pesquisado e ainda prevalece a invisibilidade do adoecimento destes profissionais. Revelam também que estes profissionais sentem-se inibidos para expressar seu sofrimento, pois, pela cultura organizacional, podem ser percebidos como frágeis e fracassados. Relataram que as mulheres estão mais vulneráveis a transtornos mentais por consequência do estresse ocupacional e o estado de alerta permanente que, apesar de não ser admitido pela maior parte dos bombeiros militares pesquisados, é uma importante fonte de estresse.

$\mathrm{O}$ reconhecimento social e os hábitos de vida saudáveis seriam as causas plausíveis identificadas por Lima, Assunção e Barreto (2015) para a baixa prevalência de depressão $(5,5 \%)$ em bombeiros militares de Belo Horizonte, Minas Gerais. Baixo controle sobre as tarefas, fraco apoio social e alta demanda física e/ou psicológica estão entre os principais agentes estressores. Aatividade física regular e a boa qualidade de sono, seriam os principais fatores protetores da saúde mental dos bombeiros militares pesquisados. A média de estresse dos bombeiros ainda é alta, embora tolerável.

Especificamente no caso do CBMPE, o estresse ocupacional já foi detectado em uma pesquisa de campo realizada por Filho, Araújo e Alves (2013). A pesquisa foi realizada com uma amostra de 15 bombeiros militares que trabalhavam no atendimento pré-hospitalar da corporação, buscando evidências da presença da Síndrome de Burnout. Apesar de não terem 
encontrado nenhum sujeito pesquisado com a Síndrome, encontraram um BM em sofrimento psíquico, um em estresse ocupacional e quatro com despersonalização, de acordo com os critérios do Maslach Burnout Inventory $(M B I)^{4}$. A relação difícil com os profissionais de saúde nos hospitais (momento de entrega das vítimas) e a falta de apoio da corporação em algumas ocorrências, foram as maiores causas de estresse organizacional (53\%). Nos $47 \%$ restantes dos pesquisados que se referiram a causas pessoais para 0 estresse ocupacional, citaram principalmente, o receio de não ter conhecimento suficiente para atender a vítima e o envolvimento emocional. Esta última causa fica evidente na transcrição do discurso de um sujeito pesquisado (p. 31): "O acidente com o avião da empresa aérea Noar. Aquilo me comoveu, por que as vítimas já estavam em óbito". Mesmo com os relatos acima, constatou-se que os pesquisados encontravam-se com a satisfação no trabalho acima da média nacional para outras profissões.

Os dados sobre estresse ocupacional em bombeiros militares ratificam a afirmação de que quando a sobrecarga de trabalho vem acompanhada de falta de autonomia, de controle, sobre a atividade há a possibilidade do adoecimento (CODO, SORATTO \& VASQUES-MENEZES, 2004). Indo além, Kelly (2006) acrescenta que além do controle, o apoio social e a estratégia de resposta comportamental ajudam a minimizar os efeitos danosos do estresse no sujeito.

Em pesquisa bibliográfica realizada por Lima e Assunção (2011) sobre prevalências e fatores associados ao TEPT em profissionais de emergência, revelou que variáveis individuais e de contexto (tipo e condições de trabalho) são considerados fatores de risco para o TEPT primário (vivenciado) ou secundário (testemunhado).

Buscando alguma correlação entre o estresse ocupacional e as dispensas médicas que afastaram bombeiros militares do serviço, foi solicitado, através de e-mail, ao Diretor de Gestão de Pessoas (DGP) e aos comandantes

\footnotetext{
${ }^{4}$ Inventário autoaplicável, com 22 itens e que utiliza a escala tipo likert. Tradução do Núcleo de Estudos Avançados de Burnoutno Brasil (NEPASB)
} 
de grupamentos de bombeiros do CBMPE, da capital e do interior, que informassem a graduação, a função, e o sexo do BM, data, motivo e quantidade de dias de dispensa ou licença médica de 2013 a 2015. A DGP já dispunha das licenças médicas acima de 90 dias, contudo, os grupamentos não tinham seus dados organizados, logo, tiveram dificuldades para enviá-los e, ainda assim, os dados estavam incompletos. Mesmo fazendo a identificação dos códigos da CID, não se conseguiu dados relevantes. De forma geral, as patologias mais comuns foram osteoarticulares (principalmente coluna vertebral e membros inferiores), viroses, cardiopatias, diabetes, hipertensão, infecções no sistema gastrointestinal e afecções na pele. Especificamente no campo dos transtornos mentais houve registros de sete casos (F10.1, F41.1, F19.2, F31.8, F43.2, F 32.1 e F22), sendo cinco no $2^{\circ}$ Grupamentos de Bombeiros Militar.

\section{AVALIAÇÃO PSICOLÓGICA}

A avaliação psicológica é a competência essencial do psicólogo, contudo, não é uma tarefa fácil e nem rápida. Muito menos "mágica", capaz de prever o futuro, como muitas pessoas acreditam. A psicologia estabelece-se como ciência através da avaliação de pessoas. É um processo científico e complexo, que utiliza diversos métodos e técnicas e que visa explicar e medir fenômenos psicológicos, sem perder de vista o contexto social e os direitos do cidadão que é submetido a ela, conforme o Conselho Federal de Psicologia (CFP). A forma de execução dependerá de vários fatores, conforme veremos a seguir ao abordarmos os critérios a serem observados durante o planejamento desta atividade.

Os testes psicológicos podem integrar os instrumentos utilizados no processo de avaliação psicológica e, são de uso exclusivo dos psicólogos: 
método ou técnica de uso privativo do psicólogo, em decorrência do que dispõe o $\S 1^{\circ}$ do Art. 13 da Lei n. ${ }^{\circ} 4.119 / 62$ (CFP, 2003, p. 2).

$\mathrm{Na}$ história da psicologia percebe-se que, no início dos anos 80, vários testes psicológicos começaram a ser aplicados inadequadamente (muitos importados e aplicados sem levar em consideração a realidade sóciohistórica e cultural brasileira) e, por consequência, perderam credibilidade de parte da população e até de psicólogos que chegavam a classificar os companheiros de profissão que usavam testes como de segunda categoria (CFP, 2007).

Para resgatar a credibilidade dos testes, o (CFP), criou em 2003, o Sistema da Avaliação de Testes Psicológicos (SATEPSI) com o objetivo de analisar os testes psicológicos disponíveis, qualificando-os e validando-os para o uso pelos psicólogos, verificando a fundamentação teórica, validade, precisão, sistema de correção e interpretação dos escores, padronização e manual com as informações (MACHADO, 2007). Esta medida eleva a qualidade das avaliações realizadas por disponibilizar aos psicólogos, instrumentos legítimos e adequados à realidade brasileira. Sendo a avaliação psicológica uma ferramenta complexa e com limites de compreensão da subjetividade humana e de possibilidade de mudança de uma realidade, o uso de instrumentos adequados proporciona intervenções que podem reduzir desigualdades sociais e até melhorar relações e condições de trabalho respeitando os direitos humanos e o compromisso social do psicólogo (CFP, 2011).

Os testes medem de forma padronizada, as diferenças entre indivíduos e as reações do indivíduo em situações diferentes. De uma forma ou de outra, há um referencial como critério de avaliação e julgamento dos escores, enquanto que na avaliação psicológica, reunindo informações de diversas fontes, a visão do ser humano é integral e contextualizada sócio-historicamente (CESCON, 2013). 
A responsabilidade do profissional que está encarregado pelo processo pode ser percebida nos princípios do código de ética do psicólogo, aprovado pela Resolução do CFP № 010/05 (CFP, 2005):

Explicar os procedimentos de forma clara e precisa, observando a capacidade de compreensão do sujeito, utilizar instrumentos aprovados pelo CFP, adequar o conteúdo dos documentos oriundos do processo de avaliação a quem vai utilizá-lo, sem descuidar do sigilo das informações, são outras condutas que ratificam o compromisso do profissional com a psicologia que busca intervenções sociais efetivas (SANTOS, 2011; SIQUEIRA \& OLIVEIRA, 2011).

\subsection{Planejamento de uma avaliação psicológica}

Uma vez explanado sobre avaliação e testagem psicológica, chegou o momento seguinte que será de aplicar estes fundamentos no planejamento de um processo de avaliação.

Compete ao psicólogo planejar e executar o processo de avaliação observando as dimensões éticas, legais e sociais, da formulação da demanda á conclusão do processo, como, por exemplo, o contexto, os propósitos da avaliação, os constructos psicológicos a serem investigados, seleção de instrumentos ao avaliando (CPF, 2003).

Indo além, Siqueira e Oliveira (2011) afirmam que uma intervenção psicológica adequada requer um processo de avaliação adequado. $O$ uso do termo "processo" vem ratificar o sentido da avaliaçãoque não é pontual e, sim, longitudinal, que busca compreender uma realidade (interação do sujeito com a sociedade) utilizando métodos, técnicas, conceitos e teorias científicas para elaborar uma síntese diagnóstica e sugerir medidas interventivas que mudem para melhor esta realidade. As autoras ainda destacam que qualquer que seja o tipo da avaliação ou o campo em que se realize, devem seguir as etapas abaixo (p. 46-47): 
-Recebimento da demanda (solicitação, queixa, pedido, motivo, entre outros).

- Caracterização do objeto de estudo (indivíduo, grupo ou organização).

-Análise da demanda - esclarecimento sobre o fenômeno psicológico a ser avaliado e levantamento inicial de hipóteses.

-Definição do objetivo da avaliação.

-Definição do tipo de avaliação a ser utilizada.

-Elaboração do planejamento técnico (estabelecimento de um método e escolha das estratégias mais adequadas a serem utilizadas).

-Enquadramento/contrato de trabalho.

-Aplicação do plano estabelecido.

- Levantamento, análise e interpretação dos dados obtidos com as diferentes estratégias utilizadas (dos instrumentos e técnicas aplicadas).

- Integração dos resultados dos instrumentos e técnicas/ pensamento clínico integrativo.

-Elaboração de enquadramento teórico correlacionado aos resultados analisados.

-Elaboração de síntese conclusiva do processo de avaliação realizado.

-Estabelecimento de proposta de intervenção.

- Elaboração de documento conclusivo da avaliação realizada.

-Escolha de metodologia adequada para a devolução dos resultados.

-Devolução de resultados.(SIQUEIRA e OLIVEIRA, 2011, PP 46-47).

$\mathrm{Na}$ elaboração do planejamento técnico, está inclusa a seleção dos instrumentos que serão utilizados na avaliação. Escolha dos instrumentos a serem utilizados na avaliação dependerá basicamente dos atributos que se quer avaliar e das características do avaliando (idade, grau de instrução, limitações físicas). Não basta o psicólogo conhecer o teste psicológico que pretende utilizar, é preciso que o instrumento tenha parecer favorável do SATEPSI, e o profissional precisa dominar a técnica para aplicação do teste e integrar os resultados obtidos com os vários instrumentos selecionados com a realidade do avaliando, para que não produza diagnósticos incompletos ou distorcidos. A entrevista psicológica ${ }^{5}$ e a observação são técnicas bastante úteis a esta função integradora, pois, conseguem complementar possíveis lacunas observadas nos resultados dos testes (MACHADO, 2007).

\footnotetext{
${ }^{5}$ Conversação dirigida a um propósito definido de avaliação (Machado, 2007, p. 29).
} 
Os dados coletados através dos instrumentos de avaliação, após cuidadosa interpretação, serão integrados em um laudo ou relatório psicológico. Considerando as consequências (positivas ou negativas) deste laudo para a vida do sujeito, ele deve conter também, se for o caso, orientações sobre encaminhamento, intervenções e acompanhamento psicológico, sendo a devolutiva dos resultados uma etapa importante do processo, às vezes, pode funcionar até como uma intervenção, conforme consta na cartilha para avaliação psicológica (CFP, 2013).

Considerando que quanto mais semelhantes foram as amostras, os contextos em que a avaliação foi realizada e os objetivos da mesma, maior será a generalização, ou seja, o resultado da avaliação do estresse ocupacional no CBMPE pode ser generalizado para outras corporações BM no Brasil.

Para que se tenha um resultado confiável, o diagnóstico psicológico deve ser completo, avaliar todos os construtos necessários e não apenas parte deles. Para isto pode-se valer dos mais variados instrumentos e técnicas (LEITE, 2011).

\subsection{Avaliação psicológica do estresse ocupacional no CBMPE}

O monitoramento do estresse ocupacional enquadra-se em uma avaliação psicológica organizacional e Machado (2011) afirma que seus resultados devem ser analisados levando-se em consideração as relações de poder presentes na organização (chefe/subordinado) e nas suas relações com outras instituições (hospitais, polícia militar, governo do Estado). As atividades profissionais acontecem em lugares específicos, sob normas específicas e com saberes específicos. Assim, como o homem é constituído pela interação do seu aparato biológico com o meio ambiente, o profissional é constituído, na organização, pela interação com a cultura e clima organizacional, logo, a avaliação psicológica do estresse ocupacional considerará fatores pessoais e 
ambientais (organizacionais) como possíveis causadores do estresse e, com isto também apresentará intervenções que afetarão ambos, bombeiro militar e corporação.

O estresse é um fenômeno multideterminado (SISTO et al, 2012) que envolve aspectos cognitivos, afetivos, sociais e biológicos, com consequências físicas, psíquicas e sociais para o homem. $\mathrm{O}$ que dizer então, do bombeiro militar que trabalha, geralmente, em ambientes inóspitos, exposto a agentes físicos, químicos e biológicos nocivos à sua saúde e ainda, por vezes, presenciando perdas de vidas e patrimônios, colocando a sua vida em perigo?

A situação narrada acima poderia fazer a profissão bombeiro militar ser muito rejeitada, contudo, o clima e a cultura organizacional fazem a diferença. Pesquisas mostram que a satisfação com o trabalho é elevada, pela atividade que exerce, pela qualidade das relações interpessoais no ambiente de trabalho, pelo reconhecimento social e da família (NATIVIDADE e BRASIL, 2006). Natividade (2009) esclarece que os bombeiros militares "consideram sua profissão perigosa e estressante, todavia gostam do que fazem, sentem-se realizados e orgulhosos de sua profissão" (p. 417).

Estas condições favoráveis amenizam, mas, não impedem o sofrimento dos bombeiros militares, daí a importância da avaliação do estresse ocupacional destes profissionais que, frequentemente, precisam tomar decisões sob elevada pressão psicológica e possuem pouca margem para erros.

Esta satisfação com o trabalho e a elevada aceitação social da profissão bombeiro militar, talvez seja a explicação para o fato de que apenas o Corpo de Bombeiros Militar de Minas Gerais tenha iniciado um programa destinado à saúde mental dos seus integrantes: Programa de acompanhamento em saúde mental dos bombeiros da Região Metropolitana de Belo Horizonte. As demais corporações BM do Brasil não possuem um programa para avaliação psicológica do estresse ocupacional. A consulta foi feita através de um ofício 
Revista Científica do Corpo de Bombeiros Militar de Pernambuco

Seção 1 - Artigos Técnico Científicos

Artigo publicado no Vol.03 №7 - Edição de JUL a DEZ 2017 - ISSN 2359-4829

Versão on-line disponivel em: http://www.revistaflammae.com.

enviado pelo presidente da Liga Nacional dos Bombeiros do Brasil (LIGABOM) para os comandantes gerais das corporações, em julho de 2015 , a pedido do comandante geral do CBMPE. As corporações reconhecem a existência do estresse ocupacional e possuem assistência psicológica com estruturas variadas, mas para intervenções reativas e não preventivas.

Segundo informações da Diretoria de Gestão de Pessoas, no CBMPE existem 2.657 bombeiros militares (oficiais e praças), sendo 191 mulheres e 2.466 homens que realizam uma avaliação psicológica, por ocasião da seleção para ingresso, baseada em um perfil profissiográfico.

3.3. Proposta de avaliação psicológica do estresse ocupacional em bombeiros militares do CBMPE.

A avaliação psicológica tem como um dos objetivos, ser um instrumento de mudança positiva do contexto que gerou a sua necessidade. Sendo o estresse ocupacional um fator intermediário entre a saúde e a doença do trabalhador, identificar o que the incomoda, Ihe causa sofrimento físico e psicológico, proporcionará medidas que reduzam acidentes de trabalho, o absenteísmo e melhore a convivência familiar e social, contribuído para a qualidade de vida do bombeiro militar.

Esta proposta foi elaborada pelo fato de que, cada vez mais, os bombeiros militares apresentam um quadro de adoecimento físico e mental, e de que há apenas uma corporação BM no Brasil que realiza o monitoramento do estresse ocupacional, e ainda assim apenas para a Região Metropolitana. Esta pesquisa por mais abrangente que fosse, não poderia apresentar um planejamento completo para realização da avaliação, pois, requereria estabelecimento de condições junto ao CBMPE (demanda, período, local, número de pessoas, custo).

Sendo o estresse ocupacional causado por múltiplos fatores, e que estes, podem ser externos (condições de trabalho e fatores situacionais) ou 
internos, do sujeito (estratégias de enfrentamento, traços de personalidade), indicam-se os testes de atenção sustentada e atenção dividida (AS e AD), o Inventário de Sintomas de Stress para adultos de Lipp (ISSL), a Escala de Vulnerabilidade ao estresse no trabalho (EVENT), aplicados nesta sequência. Para que a coleta e a interpretação dos dados, bem como, os resultados, não sofram contaminação (interferência), sugere-se que os testes sejam aplicados por psicólogos que não sejam bombeiros militares (externos à corporação).

Os testes de AS (atenção sustentada) tem por objetivo avaliar capacidade que o sujeito tem para focar a atenção em um determinado estímulo, competindo com outros, e manter a atenção por um determinado período de tempo, enquanto que o $A D$ (atenção dividida) tem por objetivo avaliar a capacidade do sujeito de manter a atenção com qualidade e concentração em dois estímulos ou mais. Habilidades essenciais para o desempenho da atividade BM com segurança, para si e para outrem. O tempo de aplicação de ambos é de aproximadamente 12 minutos no total. O ISSL viabilizará um diagnóstico diferencial dos sintomas e da fase de estresse em que o BM possa estar, separando aspectos físicos e psicológicos.

A aplicação deve ser realizada em dias de folga do BM (não entrando ou saindo de serviço), em um ambiente tranquilo, com assentos confortáveis, com iluminação e ventilação adequadas, livre de barulhos que possam interferir na concentração dos executores. No caso de aplicação coletiva, manter um espaço entre as cadeiras que permita a circulação do aplicador e evite os contatos pessoais.

Todos possuem correção online, disponibilizada pela editora, o que facilita e agiliza os resultados.

Como sugestão, a entrevista individual seria realizada apenas quando o psicólogo (a) precisasse esclarecer algum aspecto dos resultados dos testes e com os sujeitos que apresentassem sinais de estresse ocupacional, ou ainda quando fosse solicitada pelo sujeito. Todas as informações sobre os resultados 
das avaliações constariam em um laudo (individual e geral), que obedeceria ao prescrito na Resolução № 07/2003 do CFP, datada de 14 de junho de 2003.

Esta avaliação seria periódica e duraria aproximadamente um mês. Este cálculo foi estimado considerando-se o trabalho de dois psicólogos (as), avaliando um efetivo de 2.657 bombeiros militares. Aplicando em dois grupos de 20 pessoas, durante uma hora, quatro horas por dia. Em uma semana seriam avaliados 800 bombeiros militares. Quanto maior a equipe, menor 0 tempo de execução.

Os relatórios (laudos) das avaliações, pelo seu caráter preditivo, possibilitariam o encaminhamento dos bombeiros militares para tratamentos psicológicos e médicos específicos, respeitando as suas necessidades, evitando intervenções inócuas, ou pior, não realizar nenhuma intervenção (estes bombeiros seriam abordados individualmente).Os BM teriam direito de acesso aos resultados das avaliações, junto aos psicólogos (pode ser feito em grupos), momento em que as devolutivas já poderão ter um efeito terapêutico para o sujeito.

\section{CONCLUSÕES}

Apesar das inúmeras pesquisas que ratificam a presença do estresse físico e psicológico na atividade bombeiro militar, apenas uma corporação BM do Brasil, possui um programa voltado para a saúde mental dos seus integrantes, monitoramento do estresse ocupacional, e ainda assim, apenas para a Região Metropolitana, mesmo tendo ciência de que o estresse ocupacional causa sofrimento físico, psíquico e social neles.

Mesmo trabalhando em um ambiente inóspito, as pesquisas relacionadas neste estudo mostram que os bombeiros militares têm um nível de estresse ocupacional abaixo da média nacional para outras profissões. A enorme satisfação com o trabalho, somada à elevada aceitação social e à representação social de "herói", podem ser as causas deste fenômeno. A cultura e o clima organizacional são fatores protetores (coesão, qualidade das 
relações interpessoais), mas não são suficientes para evitar os efeitos danos do estresse à saúde do BM. Algumas corporações viabilizam, na instituição, ou fora dela, assistência psicológica para o BM que apresentar ou se queixar de transtornos psicológicos.

A ausência de monitoramento das causas das dispensas e licenças médicas, a falta de profissionais de psicologia em quantidade e qualidade necessárias e não perceber o "homem" por trás do mito de "herói", impedem que se trace qualquer correlação daquelas dispensas e licenças com o estresse ocupacional e, contribuem para a manutenção e agravamento de suas consequências.

O objetivo da pesquisa foi alcançado, foi apresentada a proposta de avaliação psicológica do estresse ocupacional para os integrantes do CBMPE.Esta avaliação pode ser uma valiosa ferramenta para prevenir o adoecimento físico e mental do BM (acidentes de trabalho, reduzir conflitos familiares, reduzir o alcoolismo, tabagismo e outras substâncias nocivas).

Diante do exposto, recomenda-se a realização da avaliação da tropa do CBMPE e o inicio imediato do monitoramento dos motivos de afastamento do serviço, não só do CBMPE, mas de todos os corpos de bombeiros do Brasil, através da LIGABOM. Um banco de dados nacional sobre o assunto, proporcionaria um grande avanço na política de recursos humanos das corporações, pois, as intervenções começariam nos cursos de formação com palestras e até mesmo com mudança de conteúdos nos currículos. Tais intervenções poderiam se estender aos procedimentos operacionais (equipamentos, técnicas e rotina).

A falta de dados necessários sobre dispensas e licenças médicas, além da quase inexistência de pesquisas sobre a cultura organizacional das corporações bombeiros militares, foram limitadores desta pesquisa.

A psicologia tem muito a contribuir com as corporações bombeiro militar através da realização de pesquisas de campo sobre o estresse ocupacional 
Revista Científica do Corpo de Bombeiros Militar de Pernambuco

Seção 1 - Artigos Técnico Científicos

Artigo publicado no Vol.03 №7 - Edição de JUL a DEZ 2017 - ISSN 2359-4829

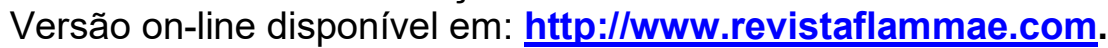

que estes profissionais sofrem. Desta forma viabilizaria a adoção de medidas (intervenções) proativas e reativas eficazes, contribuindo para o bem estar do bombeiro militar e para que, desta forma, atendam melhor à sociedade.

\section{REFERÊNCIAS}

ALCHIERI, João Carlos; NORONHA, Ana Paula Porto; PRIMI, Ricardo. Guia de referências: testes psicológicos comercializados no Brasil. São Paulo, Casa do psicólogo: 2003.

ANCONA-LOPEZ, Marília (Org.). Psicodiagnóstico: processo de intervenção. 2. ed. Seção Paulo: Cortez, 2003.

AVOGLIA, Hilda Rosa Capelão. O sentido da avaliação psicológica no contexto e pra o contexto: uma questão de direito. Psicólogo InFormação, São Paulo, v. 16, n. 16, p. 179-189, jan-dez 2012.

AZEVEDO, Israel Belo de. 0 prazer da produção científica: passos práticos para a produção de trabalhos acadêmicos. 13 ed. São Paulo: Hagnos, 2012.

BENDASSOLLI, Pedro F. e SOBOLL, Lis Andréa P. (Org.). Clínicas do trabalho: novas perspectivas para compreensão do trabalho na atualidade. São Paulo: Atlas, 2011.

BENEVIDES-PEREIRA, Ana Maria T. (Org.). Burnout: quando o trabalho ameaça o bem-estar do trabalhador. 4. ed. São Paulo: Casa do Psicólogo, 2010.

BERGER, Peter L.; LUCKMANN, Thomas. A construção social da realidade: tratado de sociologia do conhecimento. Tradução de Floriano de Souza Fernandes. Petrópolis, Vozes, 1985.

BRANDÃO, Marcos Lira. Psicofisiologia- As bases fisiológicas do comportamento. 2. ed. São Paulo: Atheneu, 2002.

BRASIL. Secretaria Nacional de Segurança Pública. Perfil dos cargos das instituições estaduais de segurança pública: estudo profissiográfico e mapeamento de competências/Secretaria Nacional de Segurança Pública, [Programa Nacional de Desenvolvimento para as Nações Unidas (PNUD)] Brasília: Ministério da Justiça, SecretariaNacional de Segurança Pública, 2012. 
Estaduais de Urgência e Emergência. 05 de novembro de 2002.

BRITO, Divino Pereira de; GOULART, Iris B. Avaliação psicológica e prognóstico de um comportamento desviante numa corporação militar. Psico-USF, v. 10, n. 2, p. 149-160, jul./dez. 2008.

BRUCK, Ney Roberto Váttimo. Psicologia nas emergências: Um estudo sobre a angústia pública e o dramático cotidiano do trauma. A psicologia das emergências: um estudo sobre angústia pública e o dramático cotidiano do trauma. Porto Alegre, 2007.195 f. Tese (Doutorado em Psicologia) - PUCRS, Fac. De Psicologia.

CAPITANEO, Daiane; RIBEIRO, Camila; SILVA, Juliano Correia da. O papel idealizado do bombeiro: e o ser humano por trás da farda. Vitalle Revista de ciências da saúde. Rio Grande/RS, 24 (1): 53-68, 2012.

CARDOSO, Cármem Maria Mota; CUNHA, Francisco Carneiro. Repensando a organização: uma abordagem psicossociológica. 2. ed. Recife: Instituto de Tecnologia em Gestão, 2005.

CARLOTTO, Mary Sandra; CÂMARA, Sheila Gonçalves. Análise da produção científica sobre a Síndrome de Burnout no Brasil. Porto Alegre, PUCRS, $v$. 39, n. 2, pp. 152-158, abr./jun. 2008.

CAVALCANTI, Carlos Bezerra. Guerreiros da paz. 5. ed. Recife: Ed. Do autor, 2007.

CESCON, Lucina França. Avaliação psicologia: passado, presente e futuro. Estudos interdisciplinares em psicologia, Londrina, v.4, n.1, junho de 2013.

CODO, Wanderley; SORATTO, Lucia; VASQUES-MENEZES, lône. Saúde mental e trabalho. In: ZANELLI, José Carlos (Org.). Psicologia, organizações e trabalho no Brasil. Porto Alegre: Artmed, 2004.

CONSELHO FEDERAL DE PSICOLOGIA (CFP). Avaliação psicológica textos geradores. Brasília: Conselho Federal de Psicologia, 2011.

Federal de Psicologia, 2013.

Cartilha da avaliação psicológica. Brasília: Conselho Código de Ética Profissional do Psicólogo. Brasília: Conselho Federal de Psicologia, 2005. 
Resolução № 007/2003. Institui o manual de elaboração de documentos escritos produzidos pelo psicólogo,decorrente de avaliação psicológica e revoga a Resolução CFP No 17/2002. Brasília: Conselho Federal de Psicologia, 2003.

Resolução No 002/2003. Define e Regulamenta o uso, a elaboração e a comercialização de testes psicológicos e revoga a Resolução CFP $n^{\circ}$ 025/2001. Alterada pela Resolução $N^{\circ}$ 005/2012 de 08 março 2012. Brasília: Conselho Federal de Psicologia, 2003.

CORPO DE BOMBEIROS MILITAR DO DISTRITO FEDERAL (CBMDF). Canção do soldado do fogo. Disponível em: https://www.cbm.df.gov.br/institucional/2012-11-13-16-53-42/19-cancao-dosoldado-do-fogo. Acesso em 31 mar. 2016.

CORPO DE BOMBEIROS MILITAR DE PERNAMBUCO (CBMPE). Estatística operacional da Diretoria Integrada Metropolitana. Disponível em: http://normatizacaocbmpe.wix.com/dimoperacoesbm\#!estatistica/c78m. Acesso em 18 abr. 2016.

COSTA, Marcos Roberto Nunes. Como normatizar trabalhos acadêmicos: projetos, monografias e artigos. 2. ed. Recife: Fundação Antônio dos Santos Abranches, 2013.

CREMASCO, Luiza; CONSTANTINIDIS, Terezinha Cid; SILVA, Viviane Angelina da.A farda é um fardo: o estresse profissional na visão dos militares do corpo de bombeiros. Cadernos de terapia ocupacional da UFSCar, São Carlos, v. 16, n. 2, p. 83-90, jul-Dez 2008.

CUNHA, Jurema Alcides. Psicodiagnóstico V. 5. ed.Porto Alegre: Artmed, 2000.

DEJOURS, Christophe; ABDOUCHELI, Elisabeth; JAYET, Christian.Psicodinâmica do trabalho, contribuições da escola Dejourianaà analise da relação prazer, sofrimento e trabalho. $7 \mathrm{~h} 1$. ed. São Paulo: Atlas, 2011.

DIAS, Reinaldo; TRALDI, Maria Cristina. Monografia passo a passo. São Paulo: Alínea, 2011.

ERTHAL, Tereza Cristina. Manual de psicometria. Rio de Janeiro: Jorge Zahar, 1987. 
FRANCO, Maria Laura Puglisi Barbosa. Análise de conteúdo. Brasília: Plano editora, 2003.

GONZALES, Rosa Maria Bracini et al. O estado de alerta: um exploratório com o corpo de bombeiros.Esc. Anna Nery, Rio de Janeiro, v. 10, n. 3, p. 370377,Dec. 2006.

FILHO, José Francisco de Arruda; ARAÙJO, Vera Lúcia Nogueira; ALVES, Maria Betânia. Salvar faz sofrer? A síndrome de Burnoutentre bombeiros militares da Região Metropolitana do Recife. In: Revista FLAMMAE. v.1, n.1, p. 8-38, Edição de JAN a JUN, 2015.

GOMES, Rui; TEIXEIRA, Fátima. Influência dos processos de avaliação cognitiva na atividade laboral de bombeiros portugueses.Psico-USF, Bragança Paulista, v. 18, n. 2, p. 309-320, maio/agosto 2013.

HELOANI, José Roberto; CAPITAO, Cláudio Garcia. Saúde mental e psicologia do trabalho. São Paulo, Perspectiva, São Paulo, v. 17, n. 2, June, 2003.

JOLY, Maria Cristina Rodrigues Azevedo et al. Análise da produção científica em painéis dos congressos brasileiros de avaliação psicológica.Avaliação Psicológica, Porto Alegre, v. 6, n. 2, dez. 2007.

LAGO, Kennyston; CODO, Wanderley. Fadiga por compaixão - O sofrimento dos profissionais de saúde. Petrópolis, RJ: Vozes, 2010.

LAMBERT, Kelly. Neurociência clínica: as bases neurobiológicas da saúde. Porto Alegre: Artmed, 2006.

LAVILLE, Christian; DIONNE, Jean. A construção do saber: manual de metodologia da pesquisa em ciências humanas; trad. Heloisa Monteiro e Francisco ettineri. Porto Alegre: Editora Artes Médicas Ltda.; Belo Horizonte: Editora UFMG, 1999.

LEITE, Otávio de Abreu. A medida no exame psicológico: reflexões sobre o significado clínico da medida. In: CONSELHO FEDERAL DE PSICOLOGIA. Avaliação psicológica - textos geradores. Brasília: Conselho Federal de Psicologia, 2011.

LENT, Robert. Cem bilhões de neurônios: conceitos fundamentais de neurociência. 2. Ed. São Paulo: Atheneu, 2010. 
LIMA, Eduardo de Paula; ASSUNÇÃO, Ada Ávila; BARRETO, Sandhi Maria. Prevalência de depressão em bombeiros. Cad. Saúde Pública, Rio de Janeiro, 31(4):733-743, abr, 2015.

Tabagismo e estressores ocupacionais em bombeiros, 2011.Revista de Saúde Pública, v. 47, n. 5, p. 897-904, 2013.

LIMA, Eduardo de Paula; ASSUNÇÃO, Ada Ávila. Prevalência e fatores associados ao Transtorno de Estresse Pós-Traumático (TEPT) em profissionais de emergência: uma revisão sistemática da literatura. Rev. Bras. Epidemiol; 14 (2): 217-230, jun.2011.

LIPP, Marilda Emmanuel Novaes. Manual do Inventário de Sintomas de stress para adultos de Lipp (ISSL). 3. ed. São Paulo: Casa do Psicólogo, 2015.

MACHADO, Adriana Marcondes. Avaliação psicológica e as relações institucionais. In: CONSELHO FEDERAL DE PSICOLOGIA. Avaliação psicológica - textos geradores. Brasília: Conselho Federal de Psicologia, 2011.

MACHADO, Adriane Picchetto. Manual de Avaliação psicológica. Curitiba: Unificado, 2007

MARCELINO, Dália; FIGUEIRAS, Maria João. A perturbação pós-stress traumático nos socorristas de emergência pré-hospitalar: influência do sentido interno de coerência e da personalidade. Psicologia, saúde e doenças, vol. 8, número 001. Sociedade Portuguesa de psicologia da saúde. Lisboa, Portugal, pp95-106. 2007.

MENDES, Ana Magnólia (Org.). Psicodinâmica do trabalho: teoria, método e pesquisa. São Paulo: Casa do psicólogo / All Books, 2007.

MENDES, Rene; DIAS, Elizabeth Costa. Da medicina do trabalho à saúde do trabalhador. Rev. Saúde públ., São Paulo, 25: 341-9, 1991.

MINAYO, Maria Cecília de Souza (Org.). Pesquisa social. Teoria, método criativo e criatividade. 30. ed. Rio de Janeiro: Vozes, 2011.

MOLINET, Fernando. Fatores de estresse ocupacional na atividade do Bombeiro Militar. Curso deFormação de Soldados. Biblioteca CEBM/SC, Florianópolis, 2011. 
Revista Científica do Corpo de Bombeiros Militar de Pernambuco

Seção 1 - Artigos Técnico Científicos

Artigo publicado no Vol.03 N07 - Edição de JUL a DEZ 2017 - ISSN 2359-4829

Versão on-line disponivel em: http://www.revistaflammae.com.

MONTEIRO, Janine Kieling et al. Bombeiros: um olhar sobre a qualidade de vida no trabalho.Psicol. cienc. prof., Brasília, v. 27, n. 3, p. 554-565, set. 2007.

MURTA, Sheila Giardini; TRÒCCOLI, BartholomeuTôrres. Stress ocupacional em bombeiros: efeitos de intervenção baseada em avaliação de necessidades. Estudos de psicologia. (Campinas), vol.24, n.1, pp. 41-51, 2007.

NASCIMENTO, Keyla Cristiane et al. Percepções acerca do estresse no trabalho de uma equipe de atendimento pré-hospitalar. Revista baiana de enfermagem, Salvador, v. 21, n 2/3, p. 9-17. 2007.

NATIVIDADE, Michelle Regina da; BRASIL, Vanderlei. A escolha profissional entre os bombeiros militares.Rev. bras. orientac. prof., São Paulo, v. 7, n. 1, p. 37-43,jun. 2006.

NATIVIDADE, Michelle Regina da.Vidas em risco: a identidade profissional dos bombeiros militares.Psicologia\& Sociedade, v. 21, n. 3, p. 411-420, 2009.

NORONHA, Ana Paula Porto. Os problemas mais graves e mais frequentes no uso dos testes psicológicos. Psicologia reflexão e crítica, pp135-142, 2002.

PASQUALI, Luiz (Org.). Técnicas de exame psicológico - TEP. Vol. I: Fundamentos das técnicas São Paulo: Casa do psicólogo / Conselho Federal de Psicologia, 2001.

PEREIRA, Ana Beatriz Braga. O trabalho humano, a sociedade e o direito do trabalho. Revista da Faculdade de Direito da Universidade Federal de Goiás. V. 17, n. 1. 1994.

PERNAMBUCO. Lei № 15.187 de 12 de dezembro de 2013. Dispõe sobre a organização básica do Corpo de Bombeiros Militar de Pernambuco. Diário Oficial do Estado № 237, Pernambuco, 13 dezembro 2013.

Secretaria de Defesa Social. Corpo de Bombeiros Militar. Manual operacional № DIM 001/14: Regulação dos serviços operacionais dos oficiais e praças do CBMPE. Aprovado pela Portaria co Comando Geral NNo DIM -014/14 de 17 de setembro 2014. Pernambuco: CBMPE, 2014.

PRESTES, Maria Luci de Mesquita. A pesquisa e a construção do conhecimento científico: do planejamento aos textos. 3. ed. 1. reimp. São Paulo: Rêspel, 2007. 260 p.

RUIZ, João Àlvaro. Metodologia científica: guia para eficiência nos estudos. 2. Ed. São Paulo: Atlas, 1986. 
SANTOS, Acácia Aparecida Angeli dos. O possível e o necessário no processo de avaliação psicológica. In: CONSELHO FEDERAL DE PSICOLOGIA. Avaliação psicológica - textos geradores. Brasília: Conselho Federal de Psicologia, 2011.

SILVA, Erika Cristina da. Estresse: um pouco da sua história, concepções teóricas e a sua relação com o adoecimento. In: LINS, Fernando; MENEZES, Walfrido (Orgs.). Múltiplos olhares em psicologia. Recife: Libertas/ Estácio FIR, 2014.

SILVA, Narbal; ZANELLI, José Carlos. Cultura organizacional. In: Psicologia, organizações e trabalho no Brasil. Porto Alegre: Artmed, 2004.

SIQUEIRA, IIma Lopes Soares de Meirelles; OLIVEIRA, Mari Ângela Calderari. O processo de avaliação psicológica. In: CONSELHO FEDERAL DE PSICOLOGIA. Avaliação psicológica - textos geradores. Brasília: Conselho Federal de Psicologia, 2011.

SISTO, Firmino Fernandes et al. Escala de vulnerabilidade ao estresse no trabalho (EVENT). São Paulo: Vetor, 2012.

SOUZA, Kátia Maria Oliveira de; VELLOSO, Marta Pimenta; OLIVIERA, Simone Santos.A profissão de bombeiro militar e a análise da atividade para compreensão da relação trabalho-saúde: revisão da literatura. In: SEMINARIO DE SAUDE DO TRABALHADOR DE FRANCA, 8., 2012, Franca.

THADEU, Sayonara Helena; FERREIRA, Maria Cristina. A validade da avaliação psicológica em um processo seletivo na área de segurança pública. Revista lberoamericana de diagnóstico e avaliação psicológica.ISSN11353848 , v.2, n.36, p.117-145, 2013

VARA, Natália; QUEIROZ, Cristina. Burnout e satisfação no trabalho em bombeiros que trabalham na área da emergência pré-hospitalar. $7^{\circ}$ Congresso nacional de psicologia da saúde. Porto, janeiro, 2008.

VERGARA, Sylvia Constant. Projetos e relatórios de pesquisa em administração. 4. Ed. São Paulo: Atlas, 2003.

ZANELLI, José Carlos (Org.). Psicologia, organizações e trabalho no Brasil. Porto Alegre: Artmed, 2004

ZAPPAROLI, Amanda dos Santos; MARZIALE, Maria Helena Palucci. Risco ocupacional em unidades de Suporte Básico e Avançado de Vida em Emergências. Revista Brasileira de Enfermagem, Brasília, v. 59, n. 1, Fev. 2006.

WEISS, Donald H. Administre o stress. São Paulo: Nobel, 1991. 